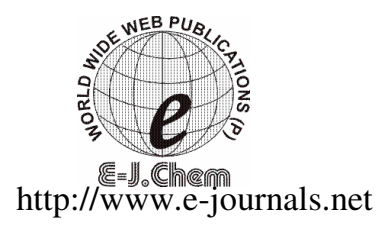

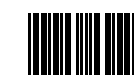

ISSN: 0973-4945; CODEN ECJHAO

E-Journal of Chemistry

2010, 7(S1), S414-S418

\title{
UV Spectrophotometric Estimation of Levoceterizine Dihydrochloride in Bulk and Dosage Form
}

\author{
P. MAMATHA, P. V.ANANTHA LAKSHMI ${ }^{*}$ and P. L. PRASUNAMBA \\ Department of Chemistry, Osmania University College for Women \\ Koti, Hyderabad, Andhra Pradesh-500001, India \\ \#Department of Chemistry, Osmania University Science College \\ Osmania University, Hyderabad, Andhra Pradesh-500007, India \\ ananthaprasad2003@yahoo.co.in
}

Received 18 April 2010; Accepted 10 June 2010

\begin{abstract}
A new simple, rapid, accurate, sensitive and precise spectrophotometric method in ultra violet region has been developed for the determination of levoceterizine dihydrochloride (LCTZ) in bulk drug and tablet dosage form. Levoceterizine dihydrochloride exhibited maximum absorbance at $232 \mathrm{~nm}$ with apparent molar absorptivity of $1.5104 \times 10^{4}$ in double distilled water. Beer's law was found to be obeyed in the concentration range of 4-20 $\mu \mathrm{g} \mathrm{mL}^{-1}$. Correlation coefficient was found to be 0.9998 . Results of the analysis were validated statistically and by recovery studies. The proposed method is useful for the routine estimation of LCTZ in bulk and tablet dosage form.
\end{abstract}

Keywords: Levoceterizine dihydrochloride, UV spectrophotometry, Beer's law, Tablet analysis.

\section{Introduction}

Levoceterizine dihydrochloride (Figure 1) is chemically 2-[4-[(4-chlorophenyl) phenyl methyl]-1- piperazinyl] ethoxy] acetic acid ${ }^{1}$ and is a highly effective anti-histamine agent. Literature survey reveals that that the drug can be estimated by HPLC, electrochemical method and spectrophotometry in visible region ${ }^{2-7}$. The present study describes a simple, sensitive, accurate, precise and economical spectrophotometric method for estimation of LCTZ in bulk and tablet formulation. UV analysis of LCTZ was performed in double distilled water. The spectrum was recorded from $200 \mathrm{~nm}$ to $400 \mathrm{~nm}$. The quantitative analysis was carried out at $232 \mathrm{~nm}$. The method was validated and applied for the determination of LCTZ in tablet dosage form. 


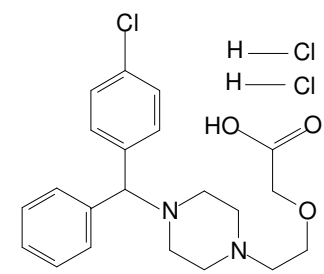

Figure 1. Chemical structure of levoceterizine dihydrochloride

\section{Experimental}

The spectrophotometric measurements were carried out using Schimadzu UV-Visible double beam spectrophotometer SL-164 with $1 \mathrm{~cm}$ matched quartz cells.

\section{Reagents}

LCTZ was tested for purity by measuring its melting point and IR spectra and no impurities were found. Double distilled water of analytical grade was used. Pharmaceutical preparations of LCTZ were obtained from local pharmacy.

\section{Standard solutions}

Standard stock solution of LCTZ $\left(1000 \mu \mathrm{g} \mathrm{m}^{-1}\right)$ was prepared in double distilled water. It was further diluted to obtain $4,6,8,10,12,14,16,18$ and $20 \mu \mathrm{g} \mathrm{mL}^{-1}$ with double distilled water. The absorbance was measured at $232 \mathrm{~nm}$ against double distilled water as blank. The calibration curve was plotted in the concentration range of 4 to $20 \mu \mathrm{g} \mathrm{mL}^{-1}$ of LCTZ.

\section{Sample solutions}

For analysis of LCTZ in tablet dosage form, four commercial brands were procured from the local pharmacy. Twenty tablets of each brand were weighed. The powder equivalent to $100 \mathrm{mg}$ LCTZ was dissolved in $20 \mathrm{~mL}$ of double distilled water, sonicated for 15 minutes and filtered through Whatman No. 41 filter paper. The filtrate was further diluted with double distilled water to $10 \mu \mathrm{g} \mathrm{mL}^{-1}$ concentrations and the absorbance was measured at $232 \mathrm{~nm}$ against double distilled water as a blank.

\section{Recovery studies}

Recovery studies were carried out by adding $1 \mathrm{~mL}$ of the $8 \mu \mathrm{g} \mathrm{mL} L^{-1}$ of standard drug solution to the preanalyzed samples. The process was repeated for five times.

\section{Results and Discussion}

The UV spectrum of standard solutions of LCTZ in double distilled water and calibration plot were illustrated in Figure 2 and 3 respectively. The optical characteristics such as Beer's law limit, molar absoptivity, slope and intercept are summarized in Table 1. The assay and precision studies results for tablets containing LCTZ are shown in Table 2. Percentage recovery was calculated from the amount of drug found in the solution. The results are given in Table 3.

\section{Validation}

The assay of LCTZ was validated with respect to stability, linearity, precision and accuracy.

\section{Linearity and range}

In developed UV method, calibration curve was linear in the range from 4 to $20 \mu \mathrm{g} \mathrm{mL}^{-1}$ of LCTZ. 


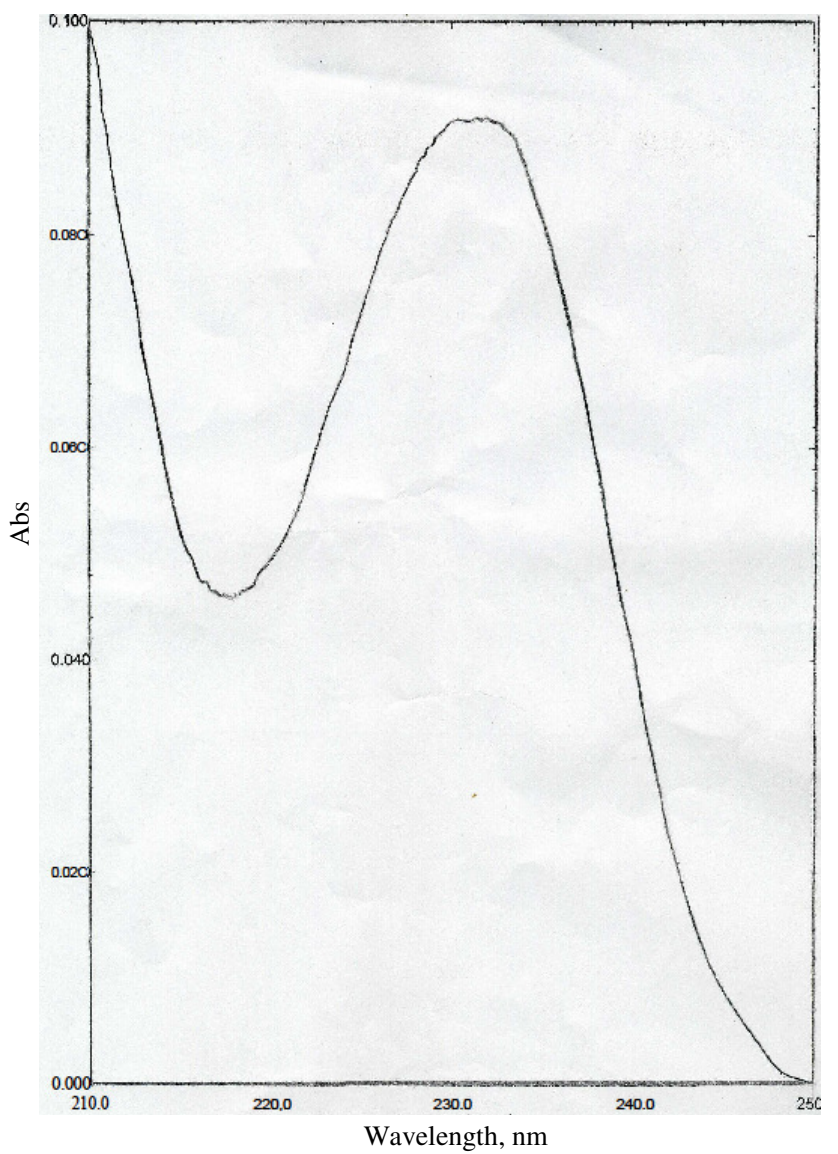

Figure 2. UV spectrum of levoceterizine dihydrochloride in double distilled water

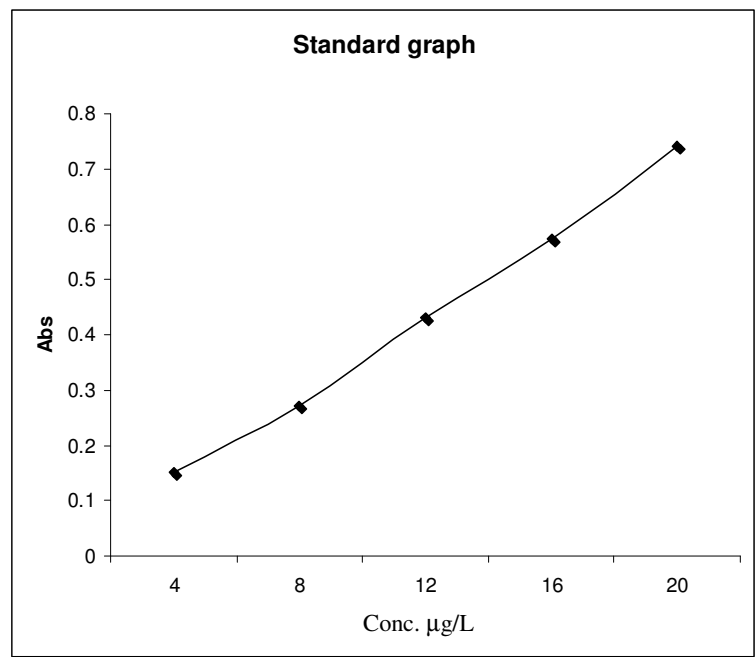

Figure 3. Calibration plot 
Table 1. Optical characteristics of proposed method

\begin{tabular}{ll}
\hline Parameters & Values \\
\hline$\Lambda$ max, $\mathrm{nm}$ & 232 \\
Beer's Law limit, $\mu \mathrm{g} \mathrm{mL} \mathrm{L}^{-1}$ & $4-20$ \\
Molar absorptivity, $\mathrm{L} \mathrm{mol}^{-1} \mathrm{~cm}^{-1}$ & $1.5104 \times 10^{4}$ \\
Regression Equation & $\mathrm{Y}=\mathrm{a}+\mathrm{bc}$ \\
Slope (b) & 0.0371 \\
Intercept (a) & -0.0119 \\
Correlation coefficient & 0.9998 \\
\hline
\end{tabular}

Table 2. Analysis of levoceterizine dihydrochloride in tablets

\begin{tabular}{cccccccc}
\hline S.No & $\begin{array}{c}\text { Tablet } \\
\text { formulation }\end{array}$ & $\begin{array}{c}\text { Label } \\
\text { claim, mg }\end{array}$ & $\begin{array}{c}\text { Amount } \\
\text { found }\end{array}$ mg & $\begin{array}{c}\text { \%Label } \\
\text { claim }\end{array}$ & $\begin{array}{c}\text { Standard } \\
\text { deviation }\end{array}$ & $\begin{array}{c}\text { Coefficient } \\
\text { of variation }\end{array}$ & $\begin{array}{c}95 \% \\
\text { Confidence level }\end{array}$ \\
\hline 1 & Brand A & 20 & 19.21 & 96.05 & 0.1649 & 2.1459 & 0.2288 \\
2 & Brand B & 20 & 20.35 & 101.75 & 0.1995 & 2.4507 & 0.2769 \\
3 & Brand C & 20 & 19.02 & 95.14 & 0.1668 & 2.1915 & 0.2315 \\
4 & Brand D & 20 & 18.93 & 94.67 & 0.1683 & 2.2223 & 0.2336 \\
\hline
\end{tabular}

*The results are mean of five readings

Table 3. Recovery studies

\begin{tabular}{cccccc}
\hline S.No & $\begin{array}{c}\text { Tablet } \\
\text { formulation }\end{array}$ & $\begin{array}{c}\% \\
\text { Recovery }^{*}\end{array}$ & $\begin{array}{c}\text { Standard } \\
\text { deviation }\end{array}$ & $\begin{array}{c}\text { Coefficient } \\
\text { of varation }\end{array}$ & $\begin{array}{c}\text { 95\% Confidence } \\
\text { level }\end{array}$ \\
\hline 1 & Brand A & 101.86 & 0.0893 & 1.0969 & 0.1240 \\
2 & Brand B & 99.06 & 0.1079 & 1.3624 & 0.1498 \\
3 & Brand C & 99.40 & 0.0689 & 0.8665 & 0.0956 \\
4 & Brand D & 99.62 & 0.1395 & 1.7510 & 0.1937 \\
\hline
\end{tabular}

*The results are mean of five readings

The proposed method for estimation of levoceterizine dihydrochloride in tablet dosage form was found to be simple, accurate, economical and rapid. Levoceterizine dihydrochloride exhibited maximum absorbance at $232 \mathrm{~nm}$ and obeyed Beer's law in the concentration range of $4-20 \mu \mathrm{g} / \mathrm{mL}$. The proposed method for levoceterizine dihydrochloride showed linear regression $\mathrm{Y}=0.0371 \mathrm{x}-0.0119$ with a correlation coefficient of 0.9998 . Relative standard deviation of $0.1649 \%, 0.1995 \%, 0.1668 \%$ and $0.1683 \%$ was observed for analysis of five replicate samples of four brands A, B, C, \& D respectively. The low values of standard deviation and $95 \%$ confidence limit indicated that the method was highly precise, accurate, reproducible and stable ${ }^{8}$. Recovery studies reveal that the values lie between $99.06 \%$ and $101.86 \%$. This indicated that there is no interference of the excipients present in formulation. Therefore this method can be used for the routine analysis of levoceterizine dihydrochloride in bulk drug and its solid dosage forms.

\section{Accuracy}

Recovery studies were performed to judge the accuracy of the method. Recovery studies were carried out by adding a known quantity of pure drug to a pre-analyzed formulations and the proposed method was followed. From the amount of drug found, percentage recovery was calculated. The results of analysis and recovery studies are given in Table 3. 


\section{Conclusion}

In this study a simple and rapid UV spectrophotometric method for the determination of LCTZ in bulk and pharmaceutical formulation has been developed and validated.

\section{References}

1. Jamie N Delgado, William A. Remers, Wilson and Gisvolds, Textbook of Organic, Medicinal \& Pharmaceutical Chemistry, $10^{\text {th }}$ Ed., Lippincott-Raven Publishers, New York, 1998, p 675.

2. Paw B, Misztal G, Hopkala H and Drozd J, Pharmazie, 2002, 57(5), 313-315.

3. Drozd J, Hopkala H, Misztal G and Paw B, Acta Pol Pharm., 2002, 59(1), 3.

4. $\quad$ Gungor S D, Pharmazie, 2004, 59(12), 929-933.

5. ElWalily A F, Korany M A, El Gindy A and Bedair M F, J Pharm Biomed Anal., 1998, 17(3), 435-422.

6. Gowda B G, Melwanki M B and Seetharamanna J, J Pharm Biomed Anal., 2001, 25(5-6), 1021.

7. Jelinska A, Stanisz B, Zajac M, Musial W and Ostrowicza, Acta Pol Pharm., 2000, 57(3), 171.

8. Shirwaikar A, Prabu S L, Kumar C D, Rajendran K, Joseph A and Shirwaikar A, Indian Drugs, 2007, 44(1), 13-15. 


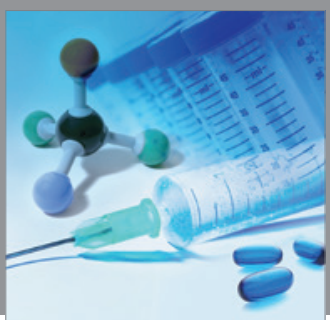

International Journal of

Medicinal Chemistry

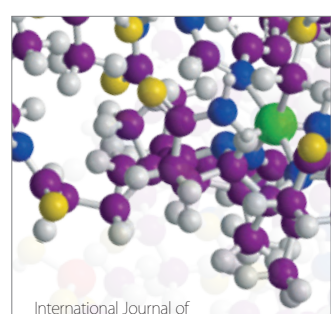

Carbohydrate Chemistry

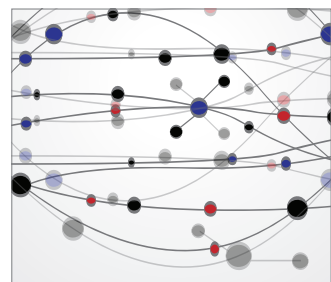

The Scientific World Journal
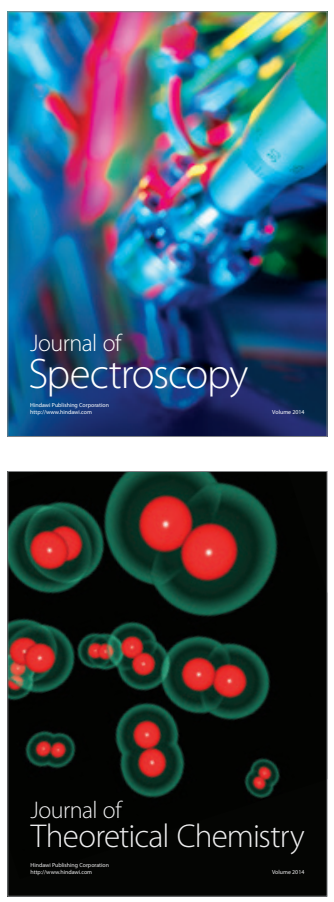
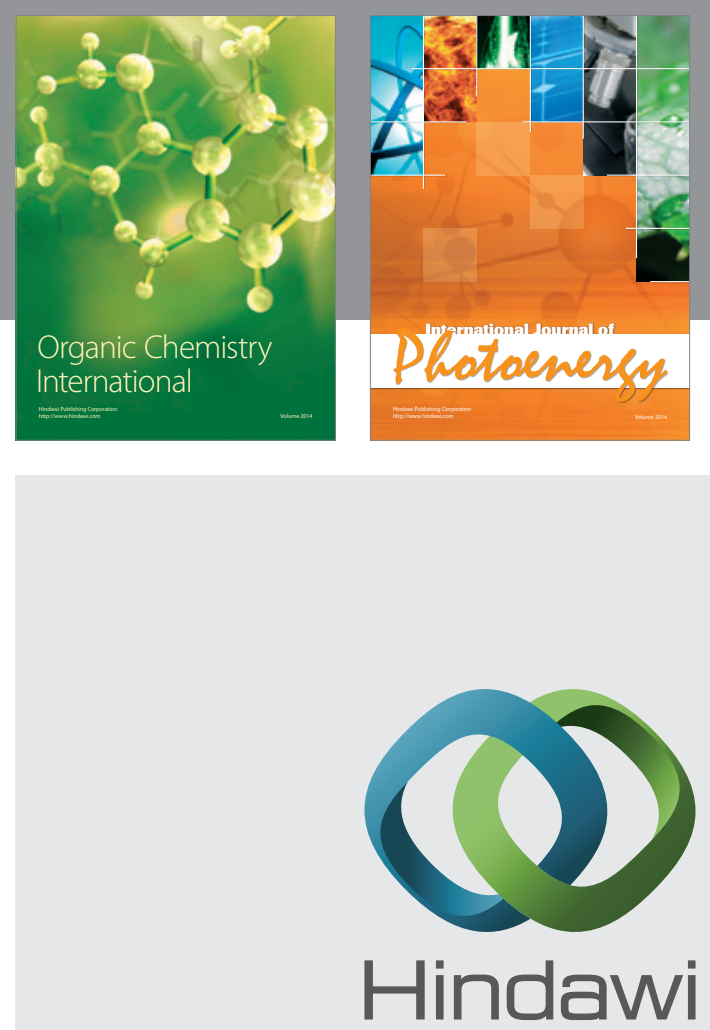

Submit your manuscripts at

http://www.hindawi.com
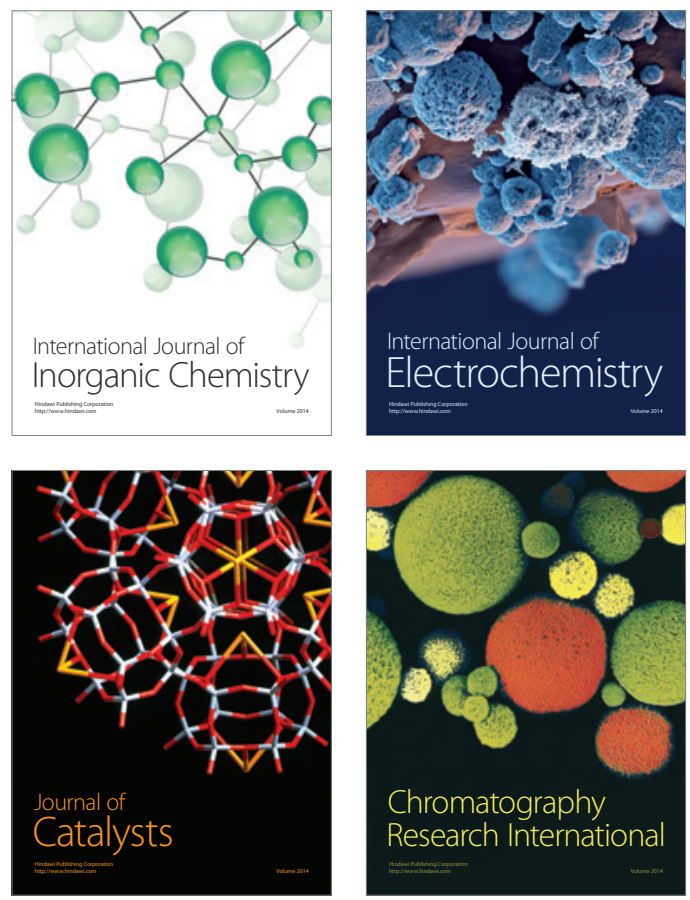
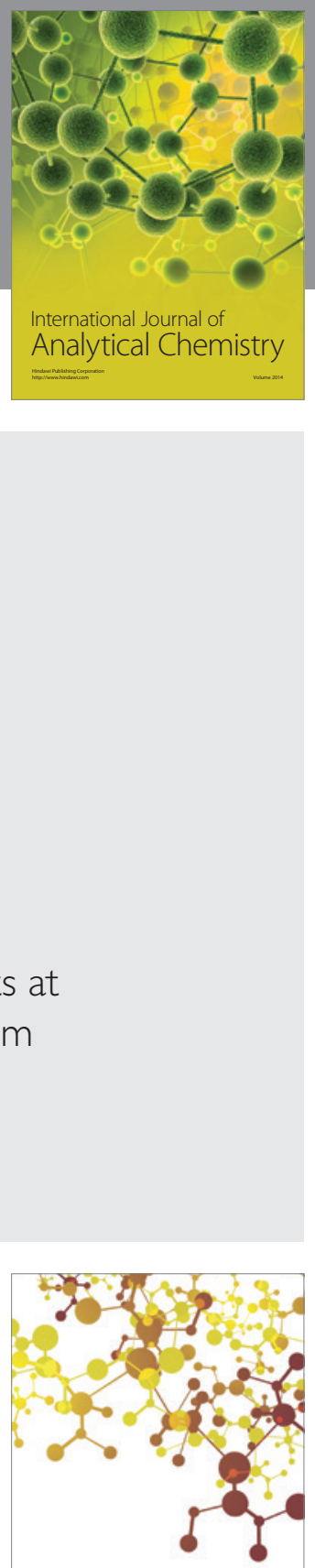

Journal of

Applied Chemistry
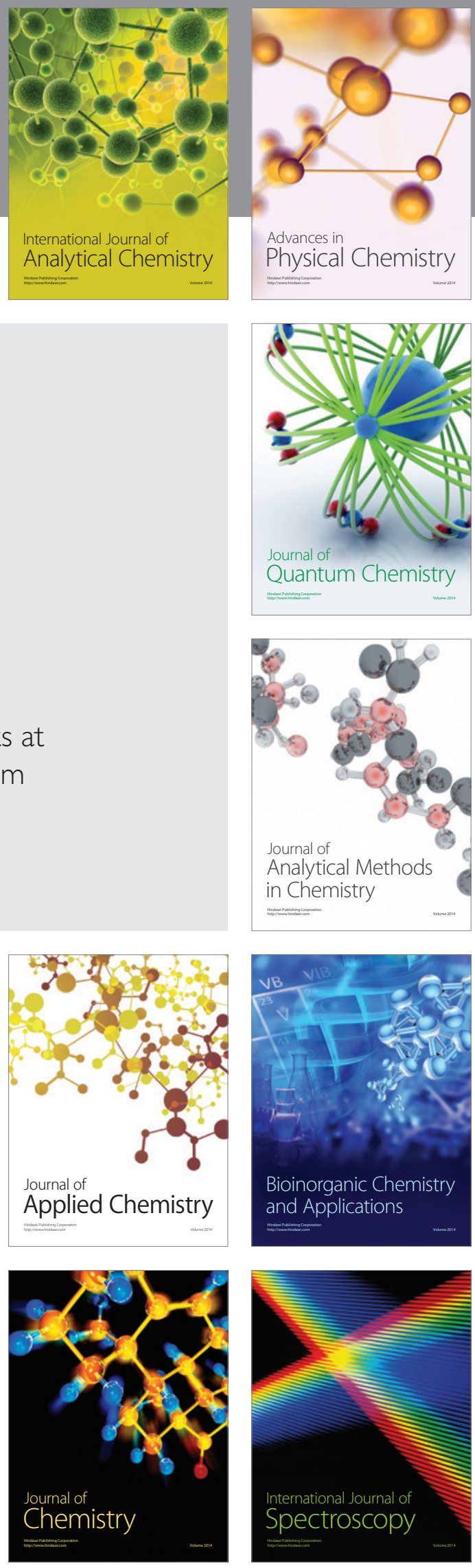